\title{
Cerebral Angiography: Not Yet Ready to Join the Dinosaurs
}

The reports of my death have been greatly exaggerated.

Mark Twain (channeling his inner angiographer ...)

read with great interest the article "Diagnostic Yield of Catheter

Angiography in Patients with Subarachnoid Hemorrhage and Negative Initial Noninvasive Neurovascular Examinations," by Delgado Almandoz et al. ${ }^{1}$ The authors reported that in patients with either convexity or diffuse SAH, the yield of catheter DSA was $10.9 \%$ for finding a causative vascular lesion when initial noninvasive vascular imaging findings with either CTA or MRA were negative. In their series, 11 patients with perimesencephalic hemorrhage did not have any lesions found on DSA that were missed on CTA or MRA.

I congratulate the authors on their work and wish to highlight some important points. This topic of whether emergent CTA should be performed on patients with SAH has been debated previously in the literature. ${ }^{2-6}$ I myself was guilty of once writing "multi-detector row CT angiography may become the method of choice for aneurysm screening in patients with acute subarachnoid hemorrhage."7 However, as our experience with CTA has matured, we still see that there is a negative predictive value of only $82 \%-96 \%{ }^{2,3}$ As such, patients with diffuse or sulcal SAH will still need DSA to exclude a causative vascular lesion. Even when an aneurysm is seen on noninvasive imaging, DSA changes the treatment plan in $19 \%-30 \%$ of patients. ${ }^{8}$ Despite many attempts to put DSA out to pasture, we see that this examination still has a vital role in the evaluation of suspected intracranial vascular lesions.

We are also entering a new paradigm in health care delivery in the United States. Instead of doing more imaging and testing, we will likely be reimbursed more for better outcomes, with payments bundled to encompass all aspects of care. As part of this cost containment, if we can eliminate a "good" test (CTA) to go directly to the "best" test (DSA), I believe that we should take this opportunity. Critics would say that CTA can be performed as an initial test, but it will likely be the case that both are performed on many patients. It is probable that the CTA could have been eliminated in many of them. Doing so may decrease the cost and will also decrease patient radiation dose. Moving forward, we as radiologists should do our part to optimize patient care by eliminating redundant testing, and when possible, directing patients to the studies most likely to impact their care.

\section{REFERENCES}

1. Delgado Almandoz JE, Crandall BM, Fease JL, et al. Diagnostic yield of catheter angiography in patients with subarachnoid hemorrhage and negative initial noninvasive neurovascular examinations. AJNR Am J Neuroradiol 2013;34:833-39

2. Li Q, Lv F, Li, et al. Evaluation of 64-section CT angiography for detection and treatment planning of intracranial aneurysms by using DSA and surgical findings. Radiology 2009;252:808-15

3. Papke K, Kuhl C, Fruth M, et al. Intracranial aneurysms: role of multidetector $\mathrm{CT}$ angiography in diagnosis and endovascular therapy planning . Radiology 2007;244:532-40

4. Kallmes DF, Layton K, Marx WF, et al. Death by nondiagnosis: why emergent CT angiography should not be done for patients with subarachnoid hemorrhage. AJNR Am J Neuroradiol 2007;28: 1837-38

5. Fox AJ, Symons SP, Aviv RI. CT angiography is state-of-the-art first vascular imaging for subarachnoid hemorrhage. AJNR Am J Neuroradiol 2008;29:e41-42, author reply e46-47

6. Moran CJ. Aneurysmal subarachnoid hemorrhage: DSA versus CT angiography-is the answer available? Radiology 2011;258:151-7

7. Jayaraman MV, Mayo-Smith WW, Tung G, et al. Detection of intracranial aneurysms: multi-detector row $\mathrm{CT}$ angiography compared with DSA. Radiology 2004;230:510-18

8. Tomycz L, Bansal NK, Hawley CR, et al. "Real-world" comparison of non-invasive imaging to conventional catheter angiography in the diagnosis of cerebral aneurysms. Surg Neurol Int 2011;2:134

M.V. Jayaraman Alpert School of Medicine at Brown University Providence, Rhode Island

http://dx.doi.org/10.3174/ajnr.A3493 